\title{
Great Metalloclusters in EnZyMology
}

\author{
Douglas C. Rees \\ Division of Chemistry and Chemical Engineering 147-75CH, Howard Hughes Medical \\ Institute, California Institute of Technology, Pasadena, California 91125; e-mail: \\ dcrees@caltech.edu
}

Key Words metalloproteins, iron-sulfur clusters, nitrogenase, hydrogenase, carbon monoxide dehydrogenase, nitrous oxide reductase

Abstract Metallocluster-containing enzymes catalyze some of the most basic redox transformations in the biosphere. The reactions catalyzed by these enzymes typically involve small molecules such as $\mathrm{N}_{2}, \mathrm{CO}$, and $\mathrm{H}_{2}$ that are used to generate both chemical building blocks and energy for metabolic purposes. During the past decade, structures have been established for the iron-sulfur-based metalloclusters present in the molybdenum nitrogenase, the iron-only hydrogenase, and the nickel-carbon monoxide dehydrogenase, and for the coppersulfide-based cluster in nitrous oxide reductase. Although these clusters are built from interactions observed in simpler metalloproteins, they contain novel features that may be relevant for their catalytic function. The mechanisms of metallocluster-containing enzymes are still poorly defined and represent substantial and continuing challenges to biochemists, biophysicists, and synthetic chemists. These proteins also provide a window into the union of the biological and inorganic worlds that may have been relevant to the early evolution of biochemical catalysis.

\section{CONTENTS}

INTRODUCTION . . . . . . . . . . . . . . . . . . . . . . . 222

Basic Features of Redox Active Metalloproteins . . . . . . . . . . . 222

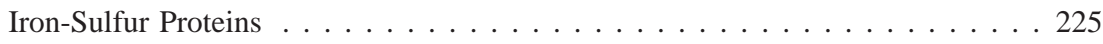

METALLOCLUSTER-CONTAINING ENZYMES . . . . . . . . . . . . 227

Nitrogenase . . . . . . . . . . . . . . . . . . . . . . . 227

Iron-Only Hydrogenase . . . . . . . . . . . . . . . . 233

Nickel-Containing Carbon Monoxide Dehydrogenase . . . . . . . . . . . 235

Nitrous Oxide Reductase . . . . . . . . . . . . . . . . . . . . . . . . 239

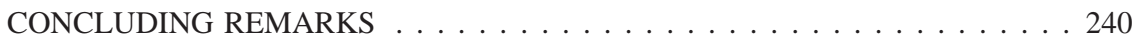

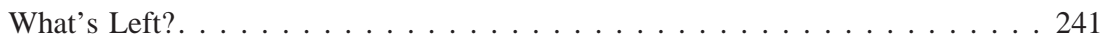




\section{INTRODUCTION}

Among the most remarkable chemical transformations in biological systems are the oxidation-reduction reactions of some of the smallest molecules, including $\mathrm{N}_{2}, \mathrm{CO}$, and $\mathrm{H}_{2}$. Redox processes involving these species not only generate basic chemical building blocks required by living organisms but can also generate the energy needed to fuel their metabolisms. Although binding sites of exquisite specificity for molecules ranging from small organic metabolites to enormous macromolecules can be constructed from the standard amino acids and nucleotides, these groups are poorly suited for binding and catalyzing the redox reactions of diatomic and similar molecules. Consequently, it is necessary to incorporate specialized metallocofactors into enzymes to provide the binding interactions for these small substrates, as well as to confer the catalytic capabilities necessary to achieve the desired transformations. Metalloclusters also provide a fascinating window into the union of the biological and inorganic worlds that may have arisen early in evolution to effect the metabolism of small molecules required to drive the energetic and growth needs of primitive organisms. Indeed, it has been proposed that before an RNA world could even exist, the central biochemical processes arose from a surface-based metabolism on the iron-sulfur-containing mineral pyrite (1). What may be the vestiges of this metabolism can perhaps still be perceived in these contemporary clusters.

This review surveys the metalloclusters that have been structurally characterized in enzymes (Figure 1). Although the choice of clusters covered is partly subjective, in general they are involved in an enzymatic activity, contain at least four metals with a minimal contribution from organic components, and are sufficiently notorious that they have been assigned a name such as $\mathrm{H}$-cluster or cluster $\mathrm{C}$ or even simply cofactor to designate a target of interest to biochemists, biophysicists, and synthetic chemists. With this definition, protein-bound bi- and trinuclear clusters catalyzing a rich variety of reactions, most notably involving dioxygen, are omitted (see 2-4 for relevant discussions), and the well-characterized iron-sulfur clusters (5) containing up to four irons are only briefly discussed as background to their more complex relatives. Following an introduction to some basic features of metalloproteins, specific metalloclusters are discussed, concluding with an overview of the general themes and features of these systems.

\section{Basic Features of Redox Active Metalloproteins}

Metallocluster-containing enzymes represent a subset of the large and varied family of metalloproteins $(2,4,6,7)$. Not surprisingly, metalloproteins contain two basic components, protein and metals. The metallo-components can consist of one or more metals, along with associated inorganic and otherwise nonprotein groups coordinated to the metals. These two basic elements interact through the protein ligands. For the metalloclusters covered in this review, the most relevant metals involve first-row transition metals, notably iron, along with nickel, 


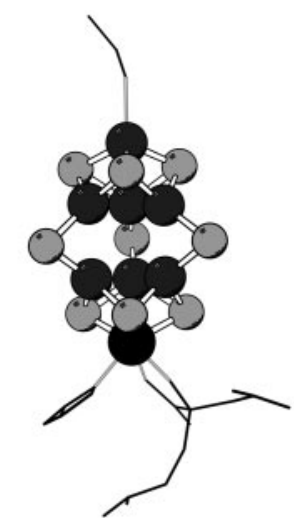

FeMo-cofactor

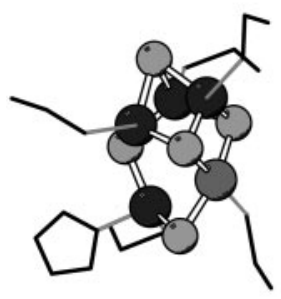

cluster C

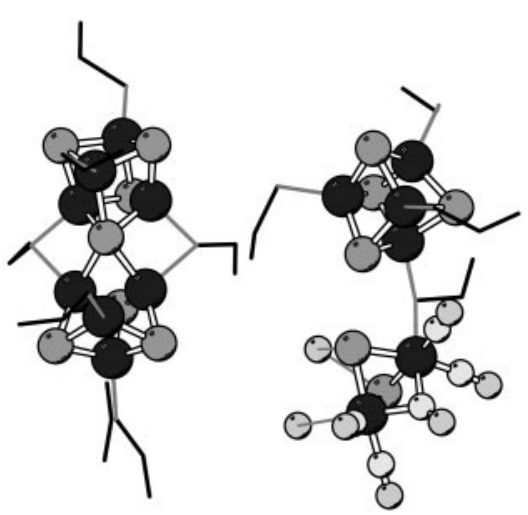

P-cluster

$\mathrm{H}$-cluster
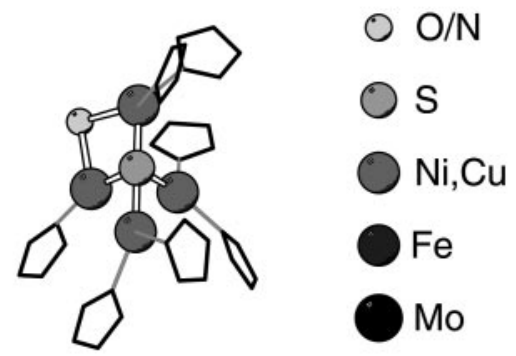

\section{CuZ center}

Figure 1 Overview of the metalloclusters discussed in this review: the FeMocofactor and P-cluster of the nitrogenase molybdenum-iron protein [Protein Data Bank (PDB) $(124,125)$ coordinate set $3 \mathrm{MIN}]$; the H-cluster of the iron-only hydrogenase (PDB coordinate set $1 \mathrm{FEH}$ ); cluster $\mathrm{C}$ of nickel $\mathrm{CO}$ dehydrogenase (PDB coordinate set 1JJY); and the CuZ center of nitrous oxide reductase (PDB coordinate set $1 \mathrm{QNI})$. Molecular figures in this chapter were prepared with the program MOLSCRIPT (126).

copper, and manganese. Occasionally, these clusters are fleshed out with a second-row transition element, molybdenum. Inorganic ligands to these metals include relatively simple species, such as sulfide $\left(\mathrm{S}^{2-}\right.$ ), water (as either $\mathrm{H}_{2} \mathrm{O}$ or $\left.\mathrm{OH}^{-}\right)$, carbon monoxide $(\mathrm{CO})$, and cyanide $\left(\mathrm{CN}^{-}\right)$; more complex molecules can also be utilized as ligands, including homocitrate and dithiols. The most common protein ligands for coordinating metalloclusters are cysteine, particularly as an iron ligand, and histidine, as a copper ligand. Typical distances for metal-ligand bonds for first-row transition metals with nitrogens in histidine side chains are 


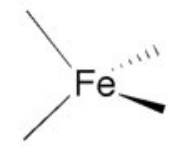

tetrahedral

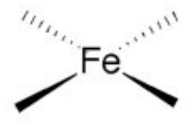

square planar
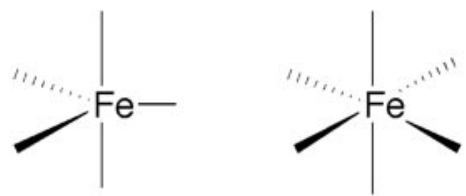

trigonal bipyramid

\section{octahedral}

Figure 2 Schematic representations of idealized coordination geometries of metal centers found in proteins.

$\sim 2.0-2.1 \AA$, and with the cysteine $\mathrm{S} \gamma$, bond distances are somewhat longer at $\sim 2.3 \AA$ (8). These distances decrease as the oxidation state increases and the coordination number decreases. By no means are metal ligands restricted to cysteine and histidine, however; examination of crystallographically characterized metalloproteins reveals that essentially any protein group that can coordinate a metal does so, from the amino-terminal nitrogen in cytochrome $f(9)$ to the carboxy-terminal carboxylate in lipoxygenase (10), and everything in between. In addition to the liganding groups, the metal coordination is generally assigned in terms of an idealized geometry (Figure 2), such as tetrahedral, trigonal bipyramid, or octahedral, although this can only be an approximate description given the asymmetric nature of the protein ligand.

Since metallocluster-containing enzymes are observed to catalyze electron transfer processes, their oxidation-reduction properties are critical to their function. The reduction potential, $\mathrm{E}^{\circ \prime}$, provides a measure of the thermodynamic tendency for an oxidized species, $\mathrm{A}_{\mathrm{ox}}$, to accept $n$ electrons and become reduced to $\mathrm{A}_{\text {red }}$ at $\mathrm{pH} 7$ :

$$
\mathrm{A}_{\mathrm{OX}}+n \mathrm{e}^{-} \rightarrow \mathrm{A}_{\text {red }} .
$$

The change in reduction potential, $\Delta \mathrm{E}^{\circ \prime}$, for a reaction is related to the standard free energy change, $\Delta \mathrm{G}^{\circ \prime}$, through the relationship

$$
\Delta \mathrm{G}^{\circ \prime}=-n \mathscr{F} \Delta \mathrm{E}^{\circ \prime},
$$

where $\mathscr{F}_{\mathrm{F}}$ is the Faraday constant that equals $23.1 \mathrm{kcal} / \mathrm{V}$ or $96.5 \mathrm{~kJ} / \mathrm{V}$. Since spontaneously occurring processes are characterized by $\Delta \mathrm{G}<0$, the equivalent condition for redox processes is $\Delta \mathrm{E}>0$. Consequently, electrons are transferred from a reduced species of lower potential to an oxidized species of higher potential (at least under standard-state conditions), which means that electrons tend to be shuttled toward groups with higher $\mathrm{E}^{\circ}$. Limits on the physiologically relevant range of $\mathrm{E}^{\circ \prime}$ values at $\mathrm{pH} 7$ and under aerobic conditions are set by the $\mathrm{H}^{+}$and $\mathrm{O}_{2}$ reduction potentials:

$$
\begin{gathered}
2 \mathrm{H}^{+}+2 \mathrm{e}^{-} \rightarrow \mathrm{H}_{2} \quad \mathrm{E}^{\circ \prime}=-0.42 \mathrm{~V} \\
1 / 2 \mathrm{O}_{2}+2 \mathrm{H}^{+}+2 \mathrm{e}^{-} \rightarrow \mathrm{H}_{2} \mathrm{O} \quad \mathrm{E}^{\circ \prime}=+0.82 \mathrm{~V}
\end{gathered}
$$




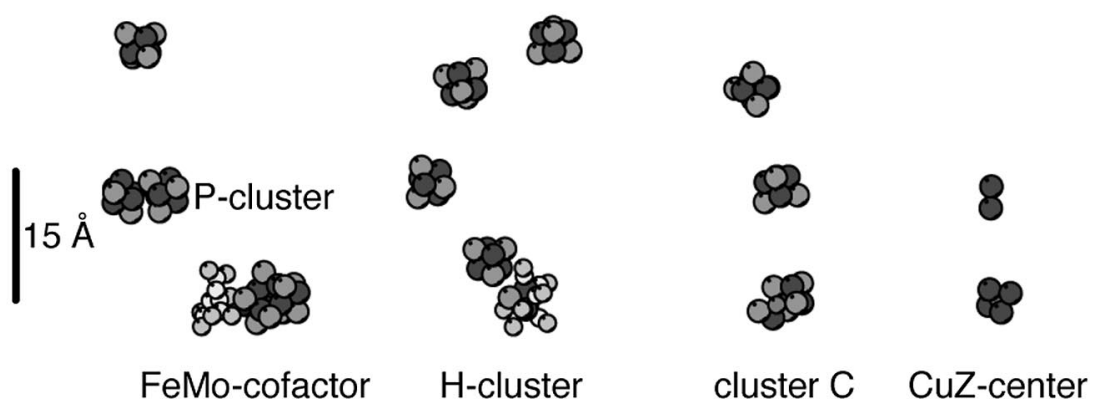

Figure 3 Sequences of electron transfer carriers in the metallocluster-containing enzymes (from left to right) nitrogenase, iron-only hydrogenase, $\mathrm{CO}$ dehydrogenase, and nitrous oxide reductase. The vertical bar on the left indicates $15 \AA$. The orientations are such that the redox centers are roughly in the plane normal to the direction of view.

In addition to thermodynamic considerations that establish the direction and driving force for electron transfer reactions, the kinetics of these processes are also crucial to the functioning of redox enzymes. Metalloclusters are incorporated into enzymes as part of a more extensive circuitry involving sequences of metallocenters that serve to shuttle electrons into and out of the active site (Figure 3). Consequently, the overall reaction rate may depend not only on the rate of the redox reaction with the substrate, but also on the rate at which electrons can be moved around. (Similar considerations apply to protons, which are often consumed or produced in these reactions.) The rate of electron transfer between two centers depends, among other factors, on their separation, with an exponential decrease in rate generally observed with increasing separation (see 11-13). Surveys of the separation between redox centers in proteins reveals a strong tendency for these centers to be separated by $\sim 10-14 \AA$ (13); the metallocluster enzymes discussed in this chapter reflect this same organizational theme. At these separations, the rates of electron transfer should be greater than $10^{6} \mathrm{sec}^{-1}$, and so exceed the range of turnover rates $\left(\sim 1 \mathrm{sec}^{-1}\right.$ to $\left.10^{4} \mathrm{sec}^{-1}\right)$ typically observed for electron transfer proteins (13).

\section{Iron-Sulfur Proteins}

Since the majority of metalloclusters discussed are in the iron-sulfur (Fe-S) cluster family, these provide an instructive starting point for discussing the interplay between the inorganic and protein worlds $(5,14-16)$. Fe-S proteins are organized around $\mathrm{Fe}$ ions that almost exclusively exhibit tetrahedral coordination to $\mathrm{S}$ ligands, provided either by the $\mathrm{S} \gamma$ of cysteines or by bridging sulfides. The basic cluster types widely observed in metalloproteins include systems with one, two, three, and four iron-containing clusters 


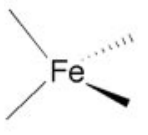

$[1 \mathrm{Fe}]$

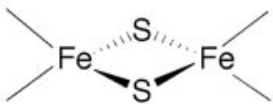

[2Fe:2S]

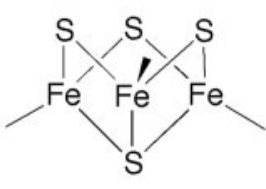

[3Fe:4S]

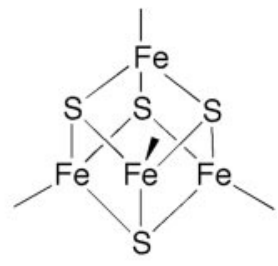

[4Fe:4S]

\section{Basic Fe-S clusters}

Figure 4 Schematic representations of the basic types of Fe-S clusters containing one to four irons.

(Figure 4). Clusters containing multiple iron atoms can be considered higher-order derivatives of the simpler $\mathrm{Fe}-\mathrm{S}$ centers. For example, the tetranuclear $[4 \mathrm{Fe}-4 \mathrm{~S}]$ clusters can be regarded as two fused binuclear iron clusters, with two terminal ligands replaced by bridging sulfides, to give a "cubane" type structure that is typically coordinated to the protein by four cysteine thiols. Trinuclear [3Fe-4S] clusters appear to be derived from [4Fe-4S] clusters by the removal of one iron. These clusters can be considered as constructed, in a formal if not a mechanistic sense, from a fundamental $\mathrm{Fe}_{2} \mathrm{~S}_{2}$ rhomb that varies relatively little in structure between different clusters. These rhombs are nearly, but not exactly, planar, as reflected in the magnitude of the S-Fe-S-Fe torsion angle of $\sim 18^{\circ}$. In a survey of highresolution structures of $[4 \mathrm{Fe}-4 \mathrm{~S}]$ clusters (17), the Fe-S, Fe-Fe, and S-S distances average $\sim 2.29 \AA, 2.68 \AA$, and $3.64 \AA$, respectively, with average $\mathrm{S}-\mathrm{Fe}-\mathrm{S}$ and $\mathrm{Fe}-\mathrm{S}-\mathrm{Fe}$ angles of $\sim 105.5^{\circ}$ and $71.8^{\circ}$, respectively.

For Fe-S clusters, the number of potential oxidation states increases as the number of metals increases. Assuming each iron can, at least formally, exist in the ferric $\left(\mathrm{Fe}^{3+}\right)$ and ferrous $\left(\mathrm{Fe}^{2+}\right)$ oxidation states, and neglecting ligand-based oxidation events, then an Fe-S cluster with $n$ irons can exhibit a maximum of $n+1$ oxidation states. To represent these states, a shorthand convention is used to describe the charge of a cluster by summing the formal oxidation states of the cluster components, while neglecting the protein ligands. For example, there are five potential states of the [4Fe-4S] clusters, ranging from the all-ferric $[4 \mathrm{Fe}-4 \mathrm{~S}]^{4+}$ form through the $[4 \mathrm{Fe}-4 \mathrm{~S}]^{3+},[4 \mathrm{Fe}$ $4 \mathrm{~S}]^{2+}$, and $[4 \mathrm{Fe}-4 \mathrm{~S}]^{1+}$ clusters to the all-ferrous $[4 \mathrm{Fe}-4 \mathrm{~S}]^{0}$ state. (In all cases, the bridging sulfides are assigned as $\mathrm{S}^{2-}$ ). The $2+$ and $1+$ states are utilized by bacterial ferredoxins; the $3+$ and $2+$ states by high-potential iron proteins (HiPIPs); and the nitrogenase iron protein can adopt the $2+, 1+$, and 0 forms. The all-ferric $[4 \mathrm{Fe}-4 \mathrm{~S}]^{4+}$ cluster has yet to be observed in proteins. In general, iron-sulfur clusters tend to have low reduction potentials with $\mathrm{E}^{\circ \prime} \approx$ $-0.4 \mathrm{~V}(15)$, and hence often participate in the reduction of other proteins or 
small molecules. The exceptions to this generalization are the HiPIPs that go between the two most oxidized forms that are observed for the four iron clusters, $[4 \mathrm{Fe}-4 \mathrm{~S}]^{3+}$ and $[4 \mathrm{Fe}-4 \mathrm{~S}]^{2+}$, and hence have relatively high potentials of $\mathrm{E}^{\circ \prime} \approx+0.35 \mathrm{~V}$, and the mononuclear rubredoxins with $\mathrm{E}^{\circ \prime} \approx 0 \mathrm{~V}$.

\section{METALLOCLUSTER-CONTAINING ENZYMES}

\section{Nitrogenase}

Nitrogenase catalyzes the reduction of atmospheric dinitrogen to the metabolically usable form of ammonia during the process of biological nitrogen fixation (for recent reviews of nitrogenase, see 18-22). The development of this activity would have been essential to supply nitrogen in a metabolically usable form for biosynthetic reactions when natural sources of fixed nitrogen were exhausted. Although the timing of this transition is uncertain, a recent proposal suggests this might have occurred following a steep fall in the rate of abiotic nitrogen fixation by lightning that accompanied decreases in atmospheric $\mathrm{CO}_{2}$ content during the Archaean period $\sim 3$ billion years ago $(23,24)$. From that time until the advent of the Haber-Bosch process for ammonia synthesis in the early part of the twentieth century, nitrogenase has provided the dominant mechanism for the production of fixed nitrogen. The industrial synthesis of ammonia has had a significant impact on agriculture and has been responsible for the ability of the Earth to sustain a substantial population increase during the last century (25).

In addition to dinitrogen reduction, nitrogenase can catalyze the reduction of protons to dihydrogen, so nitrogenase is also a hydrogenase. Indeed, the nitrogenase-catalyzed formation of hydrogen by cyanobacteria has been suggested to represent a significant contribution to the global removal of reducing power accompanying the buildup of oxygen on the Earth $(26,27)$. Nitrogenase is also able to reduce nonphysiological substrates such as acetylene that are typically small molecules with unsaturated bonds. Reduction potentials (28) for these nitrogenase substrates,

$$
\begin{gathered}
\mathrm{N}_{2}+8 \mathrm{H}^{+}+6 \mathrm{e}^{-} \rightarrow 2 \mathrm{NH}_{4}^{+} \quad \mathrm{E}^{\circ \prime}=-0.28 \mathrm{~V} \\
2 \mathrm{H}^{+}+2 \mathrm{e}^{-} \rightarrow \mathrm{H}_{2} \quad \mathrm{E}^{\circ \prime}=-0.41 \mathrm{~V} \\
\mathrm{C}_{2} \mathrm{H}_{2}+2 \mathrm{H}^{+}+2 \mathrm{e}^{-} \rightarrow \mathrm{C}_{2} \mathrm{H}_{4} \quad \mathrm{E}^{\circ \prime}=+0.23 \mathrm{~V}
\end{gathered}
$$

demonstrate that these reactions are thermodynamically favorable when coupled to the oxidation of a ferredoxin or other small protein involved in electron transfer and with a potential of $\sim-0.4 \mathrm{~V}$ or less. Despite this favorable thermodynamic assessment, substrate reduction is coupled to the hydrolysis of substantial amounts of ATP, with a limiting stoichiometry believed to be two ATPs hydrolyzed per electron transferred. The mechanistic basis for this ATP 
requirement has been extensively discussed (see 29-31) and is believed to reflect the utilization of ATP hydrolysis as a timing mechanism for driving a series of conformational changes, or for the production of super-reducing electrons.

Nitrogenase is not a single protein but actually consists of two component proteins, the iron $(\mathrm{Fe})$ protein and the molybdenum-iron $(\mathrm{MoFe})$ protein, so named for their component metals. The Fe-protein is a dimer of two identical subunits that symmetrically coordinate a single [4Fe-4S] cluster. Since the Fe-protein binds two molecules of nucleotides (MgATP or MgADP) per dimer, it is intimately associated with the coupling of ATP hydrolysis to electron transfer. The MoFe-protein is an $\alpha_{2} \beta_{2}$ heterotetramer, composed of homologous $\alpha$ and $\beta$ subunits, that contains two copies each of two extraordinary metalloclusters, the FeMo-cofactor (also called the M-cluster or simply the cofactor) and the P-cluster. The $\mathrm{M}$ and $\mathrm{P}$ nomenclature for these clusters derives from early Mössbauer spectroscopy studies that assigned iron sites to either a "magnetic" (M) or "protein" (P) cluster within the MoFe-protein (32). The nitrogenase proteins and associated metalloclusters have been extensively characterized crystallographically, with structures available for the MoFe-protein from Azotobacter vinelandii (33-36), Clostridium pasteurianum (37, 38), and Klebsiella pasteurianum (39), and for the Fe-protein from A. vinelandii $(17,40-43)$ and $C$. pasteurianum (41). Complexes of the nitrogenase proteins have been characterized crystallographically $(44,45)$ and by small-angle scattering $(46,47)$.

The P-cluster and FeMo-cofactor each contain eight metals, and their structures (Figure $5 A)(33,35,37,39)$ can perhaps be most easily visualized in terms of the juxtaposition of two [4Fe-4S] clusters, which also highlights the presence of $\mathrm{Fe}_{2} \mathrm{~S}_{2}$ rhombs in these structures. The P-cluster in the dithionite-reduced $\mathrm{P}^{\mathrm{N}}$ state can be constructed, at least mentally, by superimposing one of the sulfur atoms from each cube to create a $[8 \mathrm{Fe}-7 \mathrm{~S}]$ cluster with a hexacoordinate sulfur (defined as atom S1). The relative orientation of the two clusters can be specified from the $\sim 130^{\circ}$ angle between the Fe7-S1 and Fe3-S1 vectors that roughly coincide with the directions of the threefold axes of each cluster that contain the hexacoordinate $\mathrm{S}$. The overall symmetry of the P-cluster in this state is approximately $\mathrm{C}_{2 v}$, i.e. a twofold axis passes through the $\mathrm{S} 1$ sulfur at the intersection of two perpendicular mirror planes. The coordination spheres of the eight irons are completed by the $\mathrm{S} \gamma$ of six cysteines; four cysteines coordinate single irons and the remaining two cysteines each bridge two irons from the separate subclusters. The overall coordination geometries for all the irons in this structure are approximately tetrahedral. The quasi-twofold axis that relates the two halves of the P-cluster also extends to the protein surroundings; the P-clusters sit at the interface between an $\alpha$ and a $\beta$ subunit, which are related by this twofold axis, including the ligands.

Changes in P-cluster structure with oxidation state have been observed that deviate from this nice, symmetrical picture (35). For example, in a form of the $\mathrm{P}$-cluster that has been associated with the $\mathrm{P}^{\mathrm{OX}}$ state, which is oxidized by two electrons relative to $\mathrm{P}^{\mathrm{N}}(48,49)$, two of the irons, Fe5 and Fe6 in the subcluster 

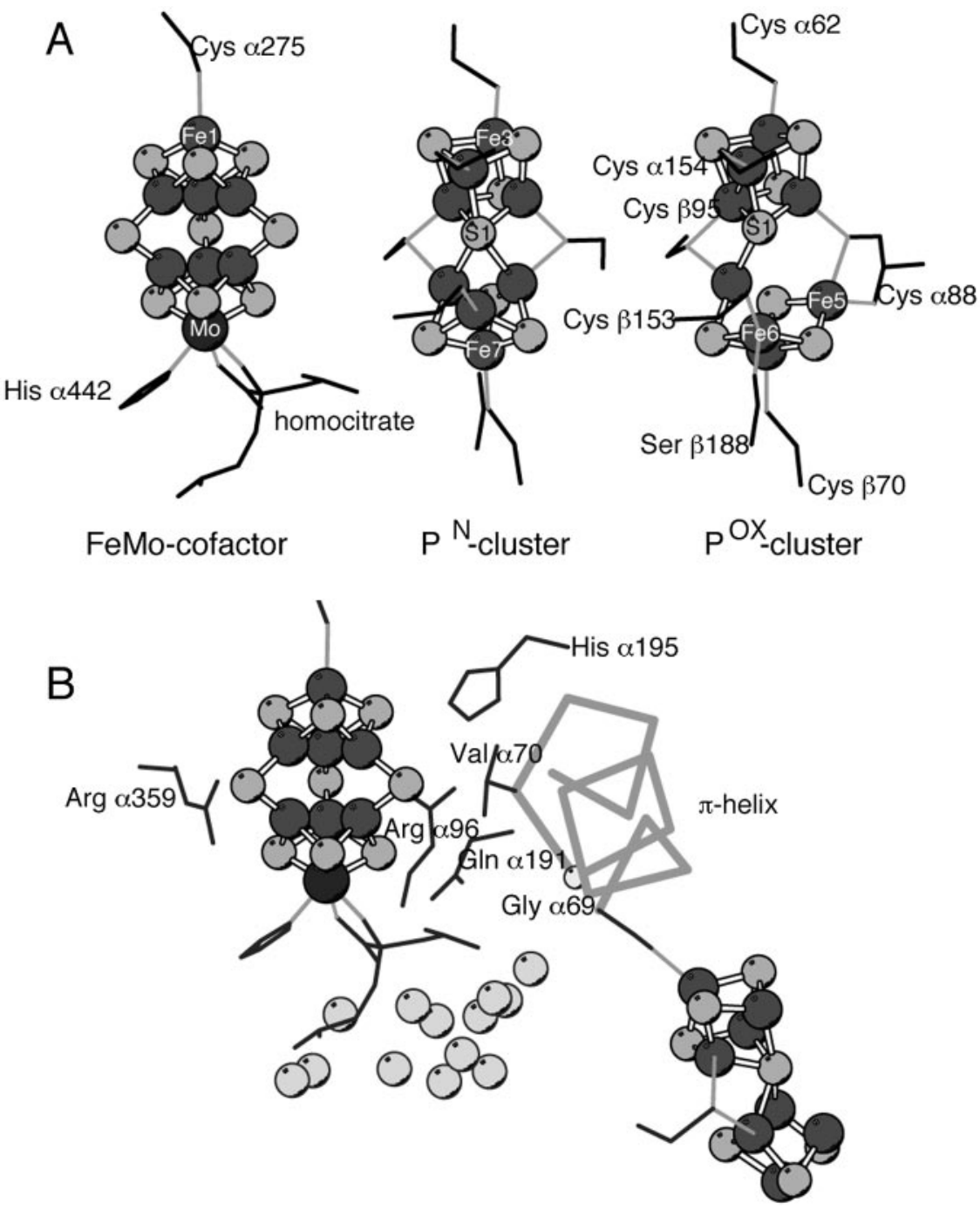

Figure 5 Structure and environment of the MoFe-protein metallocenters. (A) Structural models for the nitrogenase FeMo-cofactor and P-cluster in the $\mathrm{P}^{\mathrm{N}}$ and $\mathrm{P}^{\mathrm{OX}}$ states [PDB coordinate sets $2 \mathrm{MIN}$ and $3 \mathrm{MIN}$ ]. Liganding residues and selected cluster atoms discussed in the text are labeled. $(B)$ The environment surrounding the nitrogenase metalloclusters. Residues $\alpha 63-72$ adopt a helical conformation that extends between the P-cluster and the FeMo-cofactor, including residues $\alpha 69-74$ that form a $\pi$-helix, as defined by the program DSSP (127). Substitutions of the indicated residues have been shown to influence the substrate reduction activity of nitrogenase. The buried water molecules surrounding the homocitrate could participate in the transfer of substrates and protons to the active site. 
associated with the $\beta$ subunit, move away from the hexacoordinate sulfur. These interactions are each replaced by protein ligands, with the amide $\mathrm{N}$ of the cluster ligand Cys $\alpha 88$ and the side chain hydroxyl of Ser $\beta 188$ coordinating $\mathrm{Fe} 5$ and Fe6, respectively. Consequently, although there are changes in structure and coordinating ligands, all the irons remain four-coordinate in the $\mathrm{P}^{\mathrm{OX}}$ structure. It is possible that these changes in coordination may provide a mechanism for the coupling of proton and electron transfer processes in nitrogenase.

The overall inorganic composition of the FeMo-cofactor is [1Mo-7Fe-9S], with the whole assembly coordinated to the protein through only two residues, one attached to each end. Additional nonprotein ligands to the molybdenum are provided by a homocitrate group. Somewhat surprisingly, the FeMo-cofactor is in many ways similar in overall construction to the P-cluster, although there are several important distinctions:

1. There is no hexacoordinate sulfur in the FeMo-cofactor.

2. The threefold axes of the two subclusters are coincident, so that the overall structure has an approximate threefold symmetry.

3. The molybdenum sits on this threefold axis, coordinated to the side chain $\mathrm{N} \delta 1$ atom of His $\alpha 442$. The coordination shell of the Mo is completed by the hydroxyl and carboxylate oxygens of a homocitrate moiety to give an overall octahedral geometry.

4. The Fe site (designated Fe1) on the opposite end of the FeMo-cofactor from the Mo is coordinated by the side chain of Cys $\alpha 275$ to give an overall tetrahedral geometry.

5. Instead of being coordinated by the sulfhydryl groups of bridging cysteines, as in the P-clusters, the coordination spheres of the six remaining irons are filled by sulfurs (presumably sulfides) that bridge pairs of irons in different subclusters. As a result, these six irons are each three-coordinate, which was undoubtedly the most surprising and unexpected feature of the cofactor structure (33). The relatively short distances $(\sim 2.5-2.6 \AA)$ between irons in the different subclusters suggests that $\mathrm{Fe}-\mathrm{Fe}$ bonds are present, and it has been proposed that changes in these interactions with the number of electrons in the cofactor may be important for the binding and reduction of dinitrogen (50).

It has been not yet been possible to unambiguously establish the net charge of either the FeMo-cofactor or the P-cluster in any oxidation state, but the most likely descriptions suggest that the majority of irons in each cluster may be assigned to the reduced ferrous state. The presence of few negatively charged protein ligands to these cofactors may help stabilize what would otherwise be relatively reduced forms of iron-sulfur clusters. In the as-isolated form of the MoFe-protein prepared with dithionite, the Mössbauer spectroscopic data suggest that all the irons are ferrous in the $\mathrm{P}^{\mathrm{N}}$ state, to give an overall $[8 \mathrm{Fe}-7 \mathrm{~S}]^{2+}(51)$. A variety of other oxidized forms of the P-cluster have been identified, although forms more highly reduced than $\mathrm{P}^{\mathrm{N}}$ have not yet been described. The consensus for the FeMo-cofactor in the as-isolated $\mathrm{M}^{\mathrm{N}}$ state is that the molybdenum is in the $4+$ oxidation state; recent spectroscopic studies have been interpreted either as 
$[\mathrm{Mo}-7 \mathrm{Fe}-9 \mathrm{~S}]^{1+}$ (52), with six ferrous and one ferric (with all sulfurs as $\mathrm{S}^{2-}$ ) or as $[\mathrm{Mo}-7 \mathrm{Fe}-9 \mathrm{~S}]^{3+}(53)$, with four ferrous and three ferric irons. One-electron reduced and oxidized forms of the FeMo-cofactor, relative to $\mathrm{M}^{\mathrm{N}}$, have also been observed.

Although it is not within the stated focus of this review, the Fe-protein also exhibits unusual redox properties for a $[4 \mathrm{Fe}-4 \mathrm{~S}]$ cluster. Traditionally, this [4Fe-4S] cluster was believed to undergo a one-electron redox cycle between the $[4 \mathrm{Fe}-4 \mathrm{~S}]^{2+}$ and $[4 \mathrm{Fe}-4 \mathrm{~S}]^{1+}$ states. The ability of Fe-protein to both serve as a one-electron donor and bind two ATPs supported the idea that both ATPs are hydrolyzed during interprotein electron transfer to yield an overall $\mathrm{ATP} / \mathrm{e}^{-}$ratio of 2. More recently, an all-ferrous $[4 \mathrm{Fe}-4 \mathrm{~S}]^{0}$ form of the Fe-protein cluster has been prepared $(54,55)$, which is the first known example of this oxidation state for a $[4 \mathrm{Fe}-4 \mathrm{~S}]$ cluster, either in proteins or model compounds. Furthermore, Fe-protein is the only known example of a native, protein-bound [4Fe-4S] cluster that can exist in more than two oxidation states. Although the ability of Fe-protein to potentially serve as a two-electron donor is attractive (since all known substrates of nitrogenase are reduced by multiples of two electrons), the mechanistic relevance of the all-ferrous form of the Fe-protein remains to be definitively established; however, an $\mathrm{ATP} / \mathrm{e}^{-}$ratio near 1 with this state has been reported (56).

Although it is commonly assumed that substrates and inhibitors of nitrogenase bind to a metallocluster, most likely the FeMo-cofactor (indeed, it would be astonishing if this were not the case), direct demonstration of this binding has been exceedingly difficult for any substrate, particularly dinitrogen. Nevertheless, a variety of mechanistic proposals have been presented, inspired by model chemistry and the cofactor structure (see the collection of commentaries in 57-61). Much attention has been focused on the possible role of molybdenum as the site for substrate binding and reduction (see 62), although since the unusual coordination environment of the irons in the FeMo-cofactor was crystallographically established, the possibility that ligands may bind to one or more iron sites on the cofactor has received increasing attention (63). It is fair to say at this moment, however, that the debate is still more philosophical than scientific, as no compelling experimental studies on nitrogenase or model systems have been presented that conclusively identify the modes of substrate binding, much less the sequence of electron and proton transfer to substrates. The best-characterized ligand in terms of cluster binding properties is carbon monoxide. $\mathrm{CO}$ inhibits the reduction of all substrates, including $\mathrm{N}_{2}$, with the notable exception of $\mathrm{H}^{+}$. Hoffman and coworkers have been able to demonstrate that $\mathrm{CO}$ can bind to iron sites on the FeMo-cofactor under turnover conditions through ingenious spectroscopic experiments utilizing isotopically substituted $\mathrm{CO}$ and cofactor (64). These studies have been interpreted in terms of multiple binding modes of the $\mathrm{CO}$ to the cofactor that vary in affinity and bonding interactions (65). CO binding to the MoFe-protein has also been monitored by stopped-flow infrared spectroscopy, which again indicates the binding of multiple COs to a metallocluster (66). 
The straightforward approach to resolving this situation-addition of substrates or inhibitors to crystals of the MoFe-protein and establishing the binding sites crystallographically-is apparently precluded by the failure of substrates and other ligands to bind to MoFe-protein in the dithionite reduced state (67). Instead, substrate binding requires more highly reduced forms of the MoFeprotein that have been produced only under turnover conditions and have not been mimicked otherwise. Variants with altered substrate reduction properties may provide an approach to trapping liganded forms for crystallographic study (67a).

Mutagenesis studies have clearly indicated that substitution of residues surrounding the FeMo-cofactor can dramatically influence the substrate reduction properties of nitrogenase (68-73). Most residues surrounding the cofactor are highly conserved in various MoFe-proteins, and their substitution has definite, if not mechanistically understandable, consequences for substrate reduction. In a recent set of studies, Dean and coworkers have selected variants of the MoFeprotein that have altered substrate reduction properties (73). These studies identified a Gly $\alpha 69$ to Ser variant that can still fix dinitrogen but is less efficient at reducing acetylene. This residue is positioned in a structurally interesting region (Figure $5 B$ ); it is adjacent to $\mathrm{Val} \alpha 70$, a conserved residue sitting over one of the middle faces of the cofactor adjacent to the side chain of $\operatorname{Arg} \alpha 96$. The side chains of conserved residues His $\alpha 195$ and Gln $\alpha 191$ could also potentially interact with sulfurs on this same face, which Seefeldt and Dean have proposed represents the substrate binding site (73). Substitutions of residues in this region alter the substrate reduction properties, although so does substitution of residues in other locations around the cofactor (70). Intriguingly, residues $\alpha 69-74$ adopt a relatively rare $\pi$-helix conformation that differs from the much more common $\alpha$-helix in having an extra residue per turn. Although infrequent, $\pi$-helices have been noted to occur near active sites and regions that undergo conformational changes $(74,75)$, perhaps through hydrogen bonding interactions provided by exposed peptide groups at the ends of the $\pi$-helix.

In addition to substrates, nitrogen fixation also requires sources of electrons and protons. The likely path of electron transfer into the active site of nitrogenase was revealed in the structures of complexes between the Fe-protein and MoFe-protein, originally stabilized by $\mathrm{ADP} \cdot \mathrm{AlF}_{4}{ }^{-}$(44) and more recently with the L127 deletion variant of the Fe-protein (45). The relative positions of the metalloclusters observed in these structures indicate that electron transfer from the Fe-protein to the FeMo-cofactor proceeds through the P-clusters with edge-to-edge distances of $\sim 14 \AA$ between the three centers. Comparison of the free and bound forms of Fe-protein indicate that significant rearrangements take place in a loop that contains both cluster ligands and groups responsible for nucleotide hydrolysis, which have the net effect of pushing the cluster closer to the MoFe-protein. These considerations suggest that the conformation of this region required for ATP hydrolysis should also facilitate interprotein electron transfer, and that one role of the 
nucleotide is to orchestrate a series of conformational changes required to "open" and "close" this electron gate between the proteins. In addition to the electrons, at least eight protons are also required for the (ultimate) formation of two $\mathrm{NH}_{4}{ }^{+}$from each dinitrogen reduced, along with any protons involved in $\mathrm{H}_{2}$ evolution. The pathways of proton transfer have not been characterized, although the homocitrate, including the surrounding pool of buried waters, neighboring conserved histidines (particularly $\alpha 195$ ), and the cluster sulfurs are reasonable suspects for participating in this process (Figure $5 B$ ).

\section{Iron-Only Hydrogenase}

Hydrogenases (76-81a) catalyze one of the simplest possible reactions, namely the reversible reduction of protons to form dihydrogen:

$$
2 \mathrm{H}^{+}+2 \mathrm{e}^{-} \leftrightarrow \mathrm{H}_{2} \quad \mathrm{E}^{\circ \prime}=-0.41 \mathrm{~V} .
$$

In the direction of hydrogen evolution, the hydrogenase reaction represents a mechanism for anaerobic organisms to discharge excess reducing equivalents. In the hydrogen uptake direction, dihydrogen is used as a source of reducing equivalents to produce metabolic energy or reduced metabolites. There are two basic types of dedicated, metal-based hydrogenases: the NiFe-containing and the Fe-only hydrogenases, in addition to enzymes such as nitrogenase that apparently produce hydrogen as a side reaction. Although both hydrogenases contain interesting metallocenters, the NiFe-hydrogenase utilizes a binuclear active site, whereas the Fe-only hydrogenase contains a metallocluster that satisfies the inclusion criteria and is detailed below.

Comparison of Fe-only hydrogenases from various sources indicates that they form a homologous family organized around a common polypeptide core that coordinates the active site $\mathrm{H}$-cluster, often in combination with other domains that contain additional redox centers (reviewed in 77, 81-83). The H-cluster was so designated because it was implicated as the site of hydrogenase activity. Prior to the structure determinations of the C. pasteurianum $(\mathrm{Cp})$ and Desulfovibrio desulfuricans (Dd) Fe-only hydrogenases $(84,85)$, it was anticipated that the H-cluster contained six irons in a distinctive arrangement (see 77). The crystallographic analyses established that the $\mathrm{H}$-cluster consists of a binuclear Fe-site coordinated to a $[4 \mathrm{Fe}-4 \mathrm{~S}]$ cluster through a cysteine ligand that bridges the cluster to the proximal iron, designated Fe1 (Figure 6A). Both irons in the binuclear cluster have an octahedral coordination sphere that contains two diatomic ligands, cyanide and $\mathrm{CO}$, as indicated by infrared spectroscopic studies (86). As these ligands cannot be unambiguously distinguished crystallographically, the positioning of these diatomic groups in the structures is inferred on the basis of hydrogen bonding patterns. In the (partially) oxidized Cp structure (84), another $\mathrm{CO}$ molecule serves to bridge the two irons. Upon reduction of the $\mathrm{Dd}$ enzyme, this bridging ligand becomes a terminal ligand to Fe2 (87). One of the many intriguing facets of the $\mathrm{H}$-cluster is the presence of a still uncharacterized 
A

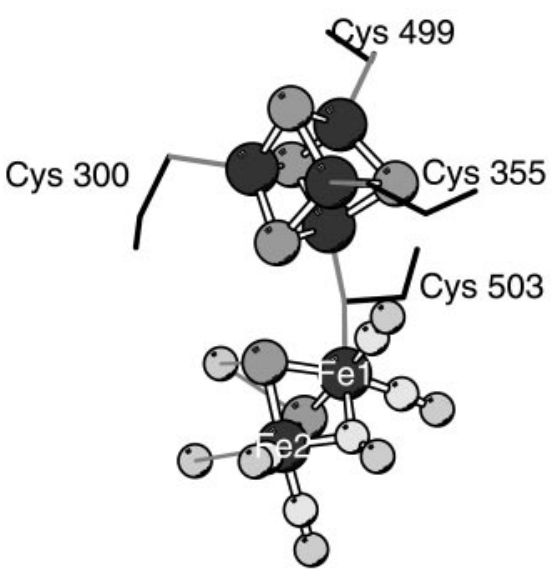

B

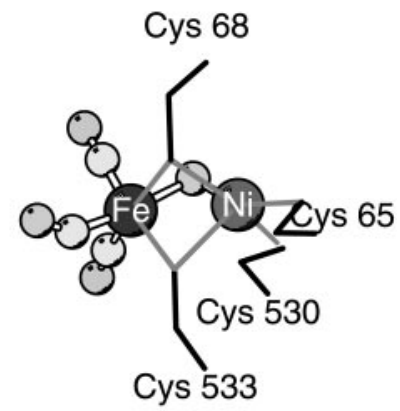

Figure 6 Active site metallocenters of hydrogenases. (A) Structural model for the $\mathrm{H}$-cluster of the iron-only hydrogenase [PDB coordinate set $1 \mathrm{FEH}]$, illustrating the relationship between the $[4 \mathrm{Fe}-4 \mathrm{~S}]$ cluster and the binuclear center, bridged by the thiol sulfur of Cys $\alpha 503$. The $\mathrm{Fe} 1$ and $\mathrm{Fe} 2$ sites are bridged by two sulfurs that are part of an incompletely characterized dithiol. The diatomic ligands species present in the coordination shell of $\mathrm{Fe} 1$ and $\mathrm{Fe} 2$ have been identified as $\mathrm{CO}$ and $\mathrm{CN}^{-}$. (B) Structure of the binuclear active site of the NiFe-hydrogenase [PDB coordinate set $2 \mathrm{FRV}]$. Although a center corresponding to the $[4 \mathrm{Fe}-4 \mathrm{~S}]$ cluster of the iron-only hydrogenase is not present, there are intriguing similarities between the two hydrogenase active sites, particularly in the presence of the diatomic ligands and the bridging thiols.

dithiol that provides two bridging sulfurs to the iron; possibilities include 1,3 propanedithiolate $(85)$ or di-(thiomethyl)-amine $(87,88)$. The final coordination site on $\mathrm{Fe} 2$ has been identified as a water in the $\mathrm{Cp}$ structure and is vacant in the Dd enzyme. Fe 2 likely provides the catalytic active site, since an inhibitory $\mathrm{CO}$ molecule has been established to bind specifically at this site $(89,90)$. This structure currently provides the only available crystal structure of a mechanistically relevant substrate/inhibitor bound to any of the metalloclusters discussed in this review.

The Fe-only hydrogenase has been shown to utilize a heterolytic mechanism that splits $\mathrm{H}_{2}$ into a proton and a hydride ion (see 76). From the crystallographic analyses summarized above, it appears likely that the site of inhibitory $\mathrm{CO}$ binding on $\mathrm{Fe} 2$ represents the site for displacement and formation of a bound hydride intermediate. Several potential proton acceptors that surround this site can participate in the transport of protons from the active site during dihydrogen 
uptake, or to the active site during dihydrogen formation. These residues are conserved between different members of this family, and they include the side chain of a lysine residue that hydrogen bonds to a putative cyanide ligand of $\mathrm{Fe} 2$, and a cysteine that interacts with the coordinated water at this site (81). The bridging sulfurs of the binuclear center could also participate in proton transfer. A hydrophobic channel that extends from $\mathrm{Fe} 2$ to the protein surface has been suggested to represent the pathway for $\mathrm{H}_{2}$ to move between the active site and the external environment (85).

Although crystallographic approaches are well suited for establishing the positions of heavy atoms, they are less well suited for establishing oxidation and protonation states of these centers, and the characterization of reaction intermediates. Theoretical treatments are not troubled by such limitations, however, and with the increasing power of computers and quantum chemical algorithms, these approaches are making increasingly important contributions to our understanding of metalloproteins. Hall and coworkers have probed the structures and energies of a variety of potential intermediates in the hydrogenase mechanism using density functional methods $(88,91)$. From these results, it is proposed that in the fully oxidized, inactive form of the Fe-only hydrogenase, both $\mathrm{Fe} 1$ and $\mathrm{Fe} 2$ are in the ferrous oxidation state. $\mathrm{H}_{2}$ is proposed to bind to a partially oxidized active site that contains an $\mathrm{Fe}^{1+}-\mathrm{Fe}^{2+}$ unit, whereas the fully reduced form involves an $\mathrm{Fe}^{1+}-\mathrm{Fe}^{1+}$ system. These conclusions provide an important cautionary tale about focusing too narrowly on just the ferrous and ferric formal oxidation states of iron in these systems. Of further interest, an analysis of the mechanism for the heterolytic cleavage of $\mathrm{H}_{2}$ implicates one of the bridging sulfur ligands in the subsequent process of proton transfer away from the active site.

Although the polypeptide folds of the NiFe-hydrogenase and Fe-only hydrogenase are distinct, there are some similarities in the nature of the active site. Crystallographic analyses of the $\mathrm{NiFe}$-hydrogenase (see 92, 93) revealed that the active site contains not only $\mathrm{Ni}$, as anticipated, but also $\mathrm{Fe}$ (Figure $6 B$ ). The $\mathrm{Ni}$ is coordinated by four cysteine residues, two of which are also ligands for the $\mathrm{Fe}$. The $\mathrm{Fe}$ is further coordinated by three diatomic ligands that have been assigned as $\mathrm{CO}$ and $\mathrm{CN}^{-}(94,95)$. A homologous protein that contains selenocysteine as one of the Ni ligands has also been studied crystallographically (96). The presence of binuclear assemblies with $\mathrm{CO}$ and $\mathrm{CN}^{-}$ligands in both classes of hydrogenases suggests there may be common mechanistic principles for these enzymes (80).

\section{Nickel-Containing Carbon Monoxide Dehydrogenase}

Although it may surprise those of us who depend on oxygen-based respiratory processes, carbon monoxide can be used as a fuel to drive metabolism by coupling the oxidation of $\mathrm{CO}$ to the reduction of an electron acceptor such as $\mathrm{H}^{+}$ in hydrogenogenic bacteria:

$$
\mathrm{CO}_{2}+2 \mathrm{H}^{+}+2 \mathrm{e}^{-} \rightarrow \mathrm{CO}+\mathrm{H}_{2} \mathrm{O} \quad \mathrm{E}^{\circ \prime}=-0.52 \mathrm{~V} .
$$


The oxidation of $\mathrm{CO}$ is catalyzed by carbon monoxide dehydrogenases (CODHs) that come in two flavors, a molybdenum-cofactor-based system found in aerobic organisms $(97,98)$ and a $\mathrm{Ni} \mathrm{CODH}$ found in anaerobic organisms (reviewed in 99-101). The former is organized around an active center containing a single molybdenum ion coordinated to the dithiolene sulfurs of a pterin ligand, whereas the latter is based on a Ni-Fe-S cluster that is detailed below.

Nickel-containing CODHs found in anaerobic bacteria consist of an unusual $\mathrm{Ni}-\mathrm{Fe}-\mathrm{S}$ center and two additional $[4 \mathrm{Fe}-4 \mathrm{~S}]$ clusters. The structural organization of this protein has recently been determined for CODHs isolated from Carboxydothermus hydrogenoformans (102) and Rhodospirillum rubrum (103). These proteins are homodimeric, with each subunit containing a catalytic cluster $\mathrm{C}$ (the $\mathrm{Ni}$ center corresponding to the site of $\mathrm{CO}$ oxidation), and a [4Fe-4S] cluster (cluster B). In addition, a previously undetected [4Fe-4S] cluster (designated cluster D to follow B and C) is symmetrically coordinated at the dimer interface by ligands from both subunits. (Although not present in these particular enzymes, certain CODHs are bifunctional and possess an acetyl-CoA synthase activity associated with cluster A.)

The structure of the cluster $\mathrm{C}$ was revealed by the crystallographic analysis at $1.6 \AA$ resolution of the $C$. hydrogenoformans $\mathrm{CODH}$ to be an unusual $[\mathrm{Ni}-4 \mathrm{Fe}-$ $5 \mathrm{~S}$ ] cluster (Figure $7 A$ ) coordinated to the protein through five cysteine and one histidine ligands (102). The structure can be imagined by first picturing a [4Fe-4S] cluster coordinated by four cysteine ligands, replacing one of the Fe by a $\mathrm{Ni}$, and then pulling apart one of the Ni-S bonds. An Fe-S unit is then inserted into this opening, with the Fe coordination sphere completed by a cysteine and a histidine; this $\mathrm{Fe}$ is labeled $\mathrm{Fe} 1$ and is in a distinctive environment relative to the other three irons. The net result is that the irons exhibit roughly tetrahedral coordination, whereas the $\mathrm{Ni}$ is approximately square planar, with three sulfides and one cysteine sulfur ligand. The integration of the Ni into the Fe-S cluster was completely unexpected, as most proposals prior to the crystal structure determination suggested that the $\mathrm{Ni}$ in cluster $\mathrm{C}$ was separated from a $[4 \mathrm{Fe}-4 \mathrm{~S}]$ cluster by bridging ligands (see 100, 104).

The overall polypeptide fold and metallocenter arrangements of the $C$. hydrogenoformans and $R$. rubrum CODHs are generally quite similar, as expected from the $\sim 55 \%$ sequence identity and $0.8 \AA$ root mean square deviation in $\mathrm{C} \alpha$ positions between these structures. Importantly, both structures agree that the Ni site is integrated into an Fe-S-containing cluster. The most intriguing distinction between the two involves cluster $\mathrm{C}$, where, in contrast to the [Ni-4Fe-5S] species identified in the $C$. hydrogenoformans $\mathrm{CODH}$, the $2.8 \AA$ resolution structure of the $R$. rubrum enzyme has been interpreted as consisting of a mononuclear $\mathrm{Fe}$ adjacent to a $[\mathrm{Ni}-3 \mathrm{Fe}-4 \mathrm{~S}]$ cluster; i.e., the overall composition of the cluster is $[\mathrm{Ni}-4 \mathrm{Fe}-4 \mathrm{~S}]$ (Figure $7 B$ ). These forms are related by removal of the sulfide that bridges the $\mathrm{Ni}$ and mononuclear $\mathrm{Fe}$ sites in the C. hydrogenoformans enzyme, followed by repositioning the Cys 531 side chain to coordinate both metals in the $R$. rubrum center. In addition to the sulfur 


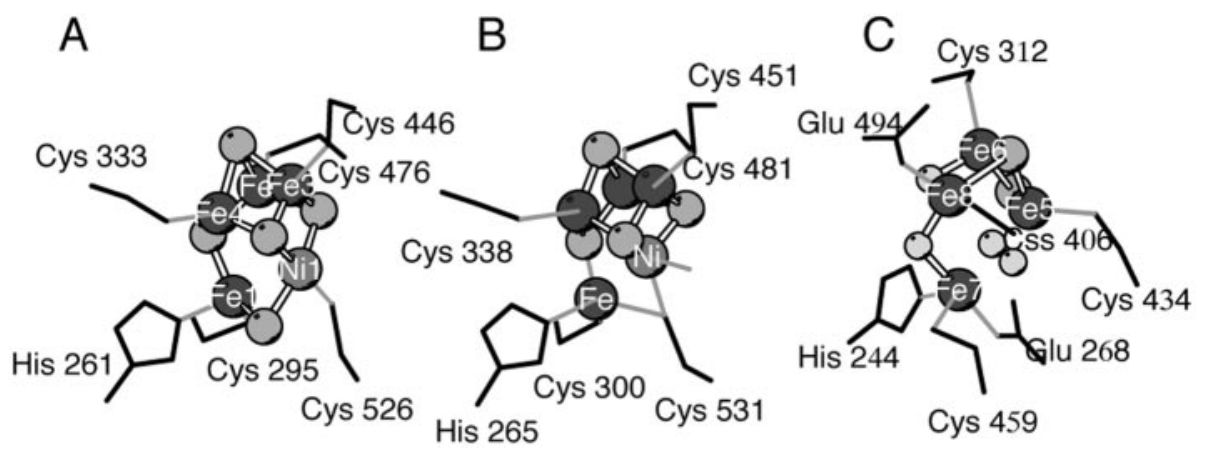

Figure 7 Active site metalloclusters of nickel CO dehydrogenase and the hybrid cluster protein. (A) Structural model of cluster $\mathrm{C}$ of the nickel-containing $\mathrm{CO}$ dehydrogenase from C. hydrogenoformans, illustrating the protein coordination [PDB coordinate set 1JJY]. Ni1 exhibits approximately square planar coordination and is believed to be the site of $\mathrm{CO}$ binding and oxidation. $\mathrm{Fe} 1$ may function in promoting nucleophilic attack of an $\mathrm{OH}$ group on the nickel-bound CO. (B) Structural model of cluster C of the nickel-containing CO dehydrogenase from $R$. rubrum [PDB coordinate set 1JQK (103)]. In comparison to the cluster in the $C$. hydrogenoformans enzyme, the sulfide bridging the $\mathrm{Ni}$ and mononuclear Fe sites is replaced through the bidentate coordination of these metals by the side chain of Cys 531. (C) Structural model of the unusual redox center in the hybrid-cluster protein (HCP) [PDB coordinate set 1E2U]. Although the function of this protein is unknown, it is homologous to the nickel-containing CODH. In particular, residues His 244, Glu 268, and Cys 459, which coordinate $\mathrm{Fe} 7$ of the HCP, correspond to the ligands for $\mathrm{Fe} 1$ and $\mathrm{Ni1}$ (His 261, Cys 295, and Cys 526, respectively) in cluster C of CODH, possibly implicating this region of the cluster in a putative substrate binding site. Of the remaining ligands, cysteines 312 and 434 and thiocysteine 406 of HCP correspond to cysteines 333, 476, and 446, respectively, of cluster $\mathrm{C}$.

content, a small, nonprotein ligand was observed coordinated to the apical site on the nickel in the $R$. rubrum CODH. Obviously, the relationship between these forms of the cluster observed in the two structures is an issue of great interest.

With the structure providing a framework for interpreting a variety of spectroscopic and biochemical data, a mechanism for $\mathrm{CO}$ oxidation has been proposed by Dobbek et al. that involves the $\mathrm{Ni}$ and Fe1 ions of cluster C (102). In the first step, $\mathrm{CO}$ binds to the vacant apical coordination site of the Ni center in the $\mathrm{Ni}^{2+}$ state to form a nickel carbonyl species. This position corresponds to the site of the small, nonprotein ligand observed in the R. rubrum $\mathrm{CODH}$ structure (103). The adjacent Fe1 state, believed to be ferrous in the active form of the enzyme, is proposed to serve as a hydroxyl-group donor for nucleophilic attack on the nickel-bound CO. Oxidation of this species leaves two electrons in cluster; as the Ni has not been observed in a paramagnetic state, it is likely that the electrons become delocalized over the cluster. The protons that are released 
in this process can be shuttled away from the active site through conserved basic residues Lys 563, His 93, and the Fe-ligand His 261 near the active site; the cluster sulfurs could also potentially participate in this process. Substrate access to and product egress from the buried active site may be mediated via a channel that extends from the surface of the dimer along all the metal clusters (102); a hydrophilic branch is suggested to be involved in water entry, and CO may approach via a hydrophobic extension. Clusters B and D are positioned to transfer the electrons produced by $\mathrm{CO}$ oxidation away from the buried active site.

Although the structure of the Mo-cofactor-containing CODH $(97,105)$ is unrelated to that of $\mathrm{Ni}-\mathrm{CODH}$, mechanistically, $\mathrm{CO}$ oxidation is proposed to proceed in both cases through attack of a metal-activated hydroxyl group on a bound $\mathrm{CO}$. In the case of the Mo-cofactor $\mathrm{CODH}$, the active site contains an unusual binuclear Mo-Cu center, with the two metals bridged by a sulfido group (105). The molybdenum is coordinated by the two dithiolene sulfurs of the pterin ligand, the sulfide group that bridges to the $\mathrm{Cu}$ site, and two oxygen (oxo or hydroxo) ligands. In a proposed reaction mechanism, the $\mathrm{CO}$ molecule enters the active site through a substrate channel to reach the oxidized $\left(\mathrm{Mo}^{6+}, \mathrm{Cu}^{1+}\right)$ active site and subsequently inserts between the $\mathrm{Cu}$ and the bridging sulfido ligand, to give an open state of the cluster with the sulfido group covalently bonded to the $\mathrm{CO}$. The carbon atom of $\mathrm{CO}$ subsequently undergoes nucleophilic attack by the Mo-OH species to generate $\mathrm{CO}_{2}$, with the Mo reduced to the $4+$ state. After release of $\mathrm{CO}_{2}$, the center is oxidized via an electron transfer chain and the hydroxo ligand is regenerated following water binding. Hence, in both the Moand Ni-containing CODHs, a catalytically important role is proposed for a set of two metals in the binding and oxidation of $\mathrm{CO}$.

The Ni-CODH exhibits a striking structural similarity to the so-called hybridcluster protein (HCP) (106-108), a protein of uncertain function most extensively characterized from Desulfovibrio vulgaris. Not only are the polypeptide folds of the two proteins quite similar, but clusters are present in HCP at the sites corresponding to the clusters $\mathrm{B}$ and $\mathrm{C}$ of $\mathrm{CODH}$. As HCP is a monomer, the corresponding cluster $\mathrm{D}$ at the dimer interface of Ni-CODH is not observed. An intriguing aspect of the HCP is the structure of an unusual cluster, designated the hybrid cluster and positioned at the site corresponding to cluster $\mathrm{C}$ of $\mathrm{CODH}$, that contains four irons, two bridging sulfurs, and two bridging oxo ligands, along with an additional disordered bridging ligand (Figure $7 C$ ). The protein coordination is rather idiosyncratic; two of the irons ( $\mathrm{Fe} 5$ and $\mathrm{Fe} 6$ ) are coordinated by single cysteine residues each and are roughly tetrahedral, Fe7 is coordinated by His, Cys, and Glu side chains, and Fe8 is coordinated by a Glu and a sulfur from an unusual thiocysteine ligand, resulting in an overall trigonal bipyramid geometry. The authors suggest that the disordered bridging ligands between Fe5 and $\mathrm{Fe} 7$ might represent the ligand binding site for an unknown catalytic activity (108). Consistent with this general assignment, the ligands to $\mathrm{Fe} 7$ are equivalent to those coordinating $\mathrm{Fe} 1$ and Ni1 in CODH. A large, mainly hydrophobic 


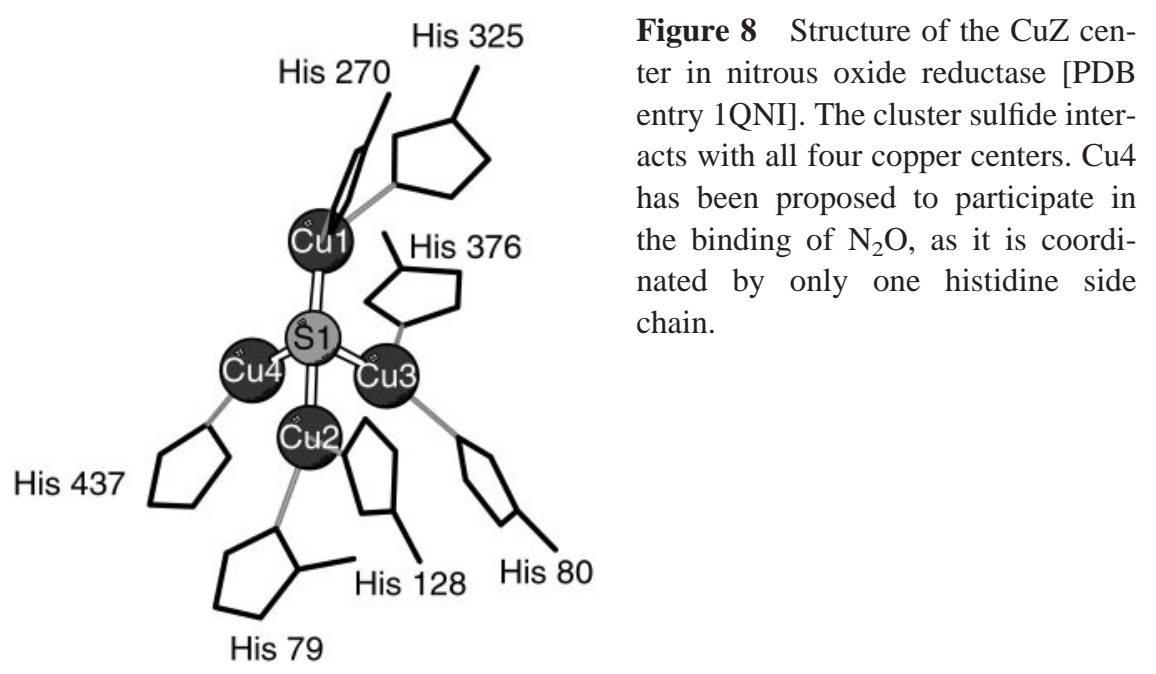

channel leads from the surface to the buried active site in the vicinity of this group.

\section{Nitrous Oxide Reductase}

The nitrous oxide reductase (N2OR) of denitrifying bacteria catalyzes the final step in the nitrogen cycle, the reduction of nitrous oxide $\left(\mathrm{N}_{2} \mathrm{O}\right)$ to dinitrogen, thereby returning fixed nitrogen to the atmosphere (reviewed in 109-112):

$$
\mathrm{N}_{2} \mathrm{O}+2 \mathrm{H}^{+}+2 \mathrm{e}^{-} \rightarrow \mathrm{N}_{2}+\mathrm{H}_{2} \mathrm{O} \quad \mathrm{E}^{\circ \prime}=+1.36 \mathrm{~V} .
$$

This is an energetically favorable transformation in which $\mathrm{N}_{2} \mathrm{O}$ serves as a terminal acceptor for a nitrate/nitrite-based respiratory process. This reaction is also of environmental relevance since it prevents atmospheric release of $\mathrm{N}_{2} \mathrm{O}$, which is a greenhouse gas.

$\mathrm{N} 2 \mathrm{OR}$ is a homodimeric protein containing two types of centers, $\mathrm{CuA}$ and $\mathrm{CuZ}$, with $\mathrm{CuZ}$ associated with the active site for nitrous oxide reduction and $\mathrm{CuA}$ playing an electron transfer role. Until recently, N2OR would not have been included in a review focusing on metalloclusters, since both centers were originally believed to be binuclear. Crystallographic analyses of the N2OR from Pseudomonas nautica (113) and Paracoccus denitrificans (114) have established, however, that whereas $\mathrm{CuA}$ contains the expected two coppers, $\mathrm{CuZ}$ is actually an unusual tetra-copper cluster of previously unsuspected structure (Figure 8). In the most recent structural results, the coppers in $\mathrm{CuZ}$ exhibit a butterfly arrangement with $\mathrm{Cu}-\mathrm{Cu}$ distances ranging from $\sim 2.5 \AA$ to $\sim 3.4 \AA$. One of the copper ions, designated $\mathrm{Cu} 1$, is somewhat more distant from the three other coppers. An inorganic sulfur $(114,115)$ bridges the four coppers, and a bridging oxygen 
ligand, possibly hydroxo, has been assigned between $\mathrm{Cu} 1$ and $\mathrm{Cu} 4$. The coordination spheres are completed by seven histidine side chains; three coppers are liganded by two histidines each, and $\mathrm{Cu} 4$ is coordinated by a single histidine ligand. In general, each copper is roughly coplanar with the coordinating ligands.

$\mathrm{N}_{2} \mathrm{O}$ can potentially bind to the catalytic site through either the terminal oxygen or nitrogen ends of the molecule, or possibly side-on. Although no structure is available for a ligand bound to N2OR, it has been suggested (113) that $\mathrm{Cu} 4$ represents the likely coordination site for substrate binding, since it has only one His residue and coordinates the bridging oxygen species. $\mathrm{N}_{2} \mathrm{O}$ has been proposed to bind via the oxygen to $\mathrm{Cu} 4$, which is suggested to be in the $\mathrm{Cu}^{2+}$ state in the reduced cluster; the transfer of two electrons from the $\mathrm{CuZ}$ cluster to the substrate results in cleavage of the $\mathrm{N}-\mathrm{O}$ bond, liberating $\mathrm{N}_{2}$, with water released following proton transfer. A mechanistic alternative has been suggested (115) in which the O may be transferred to sulfur to create a sulfoxide that is subsequently reduced. The proper oxidation state of the $\mathrm{CuZ}$ cluster for activity is restored following electron transfer from the $\mathrm{CuA}$ cluster coordinated to the adjacent subunit.

\section{CONCLUDING REMARKS}

At the current level of biochemical understanding, it appears that the metalloclusters discussed in this chapter are specialized for a unique catalytic activity; i.e., in contrast to porphyrins or flavins that function in diverse enzymatic roles, the FeMo-cofactor has been found only in nitrogenase, the H-cluster in iron-only hydrogenases, etc. Despite these specialized roles, however, several common features beyond their participation in multielectron redox reactions are present in the structure and properties of these metalloclusters:

- Although the basic stereochemical principles exhibited in the structural organization of metalloclusters are evident in simpler metalloproteins, the integration of these substructures into the complete assembly introduces exotic and unanticipated features that may be relevant for catalytic activity. For example, the dominant feature of the Fe-S-based metalloclusters is tetrahedrally coordinated Fe sites with metal-ligand distances and angles typical of those observed in simpler iron-sulfur clusters. Deviations from this behavior appear to be key elements of catalytic capability, however, and include the integration of $\mathrm{Ni}$ into the $\mathrm{Fe}-\mathrm{S}$ cluster in $\mathrm{CODH}$, the presence of octahedrally coordinated $\mathrm{Fe}$ with diatomic ligands in the iron-only hydrogenase, or, more speculatively, the trigonally coordinated Fe sites in the FeMo-cofactor.

- A common element of all these metalloclusters is the presence of sulfur, either as a cysteine ligand or as a bridging sulfide, which serves as a chemical glue to bond the components of the cluster together. The properties of sulfur have many important consequences for metalloclusters (see 15, 79, 116); the formation of covalent bonds permits intimate coupling of ligand and metal orbitals 
essential for delocalization of electrons; sulfur is a redox active ligand, so that it can participate directly in redox reactions; the ability of sulfur to serve as a proton acceptor may have important mechanistic implications; and finally, sulfur can potentially serve as a nucleophile to chemically attack substrates.

- Metalloclusters are incorporated into enzymes as part of a more extensive circuitry involving sequences of redox centers that serve to shuttle electrons in and out of the active site. These centers are typically spaced 10-14 $\AA$ apart (13) and connect the active site with the surface binding sites for the partner proteins in electron transfer. The passage of electrons along this chain has parallels to the single-file motion of ions through the pores of ion channels with multiple binding sites $(117,118)$. Intriguingly, these chains often involve redox groups coordinated to different subunits in an oligomer.

- As protons are typically either generated or consumed during metalloclustercatalyzed reactions, proton transfer chains are required to shuttle protons between the solvent and the buried metallocluster. These processes can have a significant influence on the reaction kinetics, as recently established in exquisite detail for coupled proton and electron transfers to a buried [3Fe-4S] cluster in a ferredoxin (119).

- Although the polypeptide folds of these metallocluster-containing enzymes are all distinct, the Fe-S-containing proteins utilize a common Rossmann-type motif consisting of four parallel $\beta$-strands, arranged in the order $2-1-3-4$ and flanked by $\alpha$-helices, to provide many of the coordinating ligands (Figure 9). (In contrast, N2OR adopts a $\beta$-propeller fold (113) that, though also common, is distinct from the Rossmann fold.) Curiously, although ferredoxins containing a [4Fe-4S] or a [3Fe-4S] cluster may be considered the prototype of Fe-S proteins, and although the ferredoxin-type fold is one of the most common folds exhibited by polypeptides (120), this fold has not yet been found to be involved in the coordination of complex metalloclusters. The construction of these proteins from domains and multiple subunits also provides an opportunity for channels to exist at various interfaces for substrates and products to move between the active site and surface.

\section{What's Left?}

During the past decade, many of the most prominent metalloclusters have been structurally defined. Despite the seductive appeal of the detailed molecular descriptions provided by these studies, significant gaps remain in our mechanistic understandings of these systems. As described in this review and elsewhere [see (20)], however, recent advances in the biochemistry, molecular biology, model chemistry, and theoretical analysis of metalloclusters, coupled with the ability to conduct increasingly sophisticated spectroscopic analyses and to determine increasingly accurate structures, provide grounds for optimism that detailed mechanistic descriptions will be forthcoming. A particularly significant development toward this goal will be the ability to quantitatively prepare and maintain the appropriate oxidation states of metalloclusters required for ligand binding; this capability will greatly facilitate the structural and spectroscopic characterization of liganded species that 

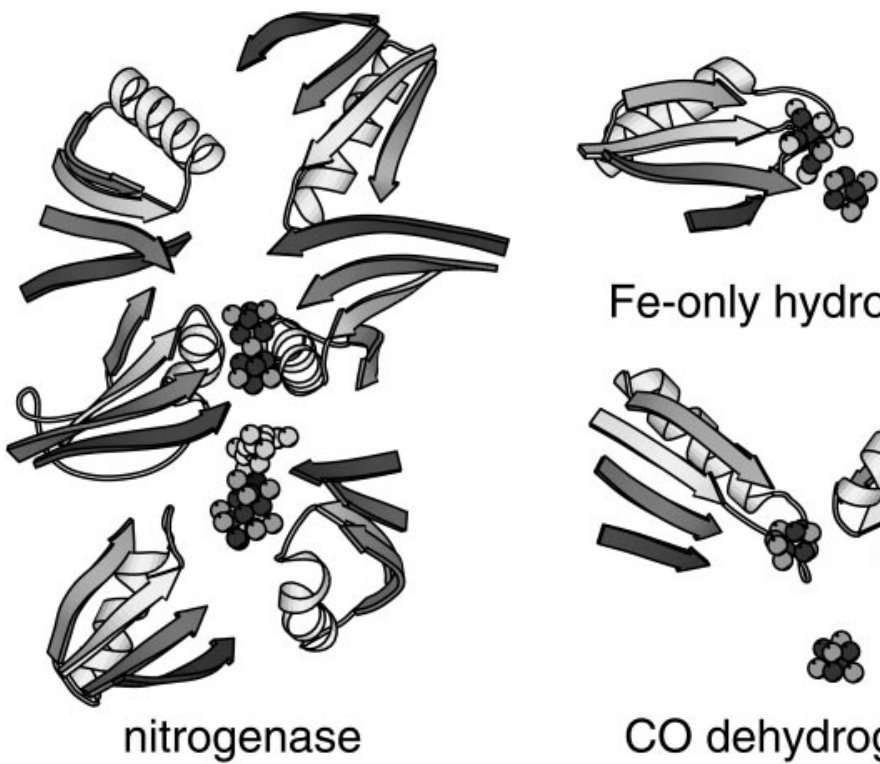

Fe-only hydrogenase

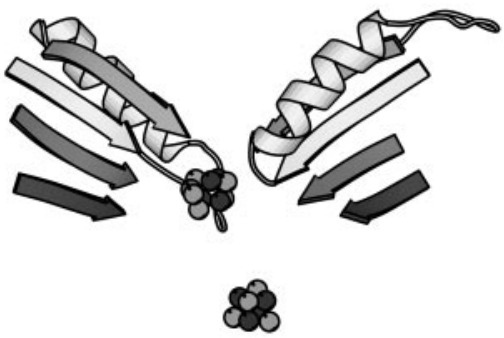

CO dehydrogenase

Figure 9 Ribbon diagram illustrating a common structural motif associated with coordination of Fe-S-related metalloclusters in nitrogenase, Fe-only hydrogenase, and $\mathrm{CO}$ dehydrogenase. This motif consists of a four-stranded, parallel $\beta$-sheet surrounded by $\alpha$-helices. The order of strands in the sheet is 2-1-3-4, with the shading of the strands progressing from strand 1 (lightest) to strand 4 (darkest). Only the $\alpha$-helix between $\beta$ strands 1 and 2 is illustrated for clarity. The protein ligands to the cluster are typically found in the loops positioned between strands 3 and 4, and after strand 4.

have so far been problematic to generate. In addition to these mechanistic issues, the syntheses of these metalloclusters, both in the biological and chemical arenas, remains a fascinating and challenging problem.

Despite the advances of the past decade, the list of metalloclusters awaiting detailed structural characterization is by no means exhausted. Perhaps the most outstanding case is the tetra-manganese-containing, oxygen-evolving complex of photosystem II; tantalizing glimpses have been yielded by crystallographic analyses at $4-\AA$ resolution (121) that have defined, at least in outline, the overall shape of this center. An engaging analysis of the possible structure(s) for this center has recently appeared (121a). Establishing the structure of the oxygen-evolving complex will be a significant step in understanding the mechanism of photosynthetic oxygen evolution, which has had dramatic geobiological consequences. The copper-containing $\mathrm{C}$ and $\mathrm{E}$ centers of the particulate methane monooxygenase (122) are also likely to reveal novel arrangements of metals that are able to catalyze the hydroxylation of methane to methanol. In addition to mature cofactors, characterization of various assembly intermediates will be significant in analyzing the biosynthetic mechanisms 
of cluster formation; the cofactor synthesized by the protein product of the NifB gene that provides iron and sulfur for the FeMo-cofactor of nitrogenase (123) is perhaps the most notable target. Even after the structures of these clusters have been solved, the ranks of the great metalloclusters will undoubtedly continue to expand with increasing characterization of microorganisms that grow in extraordinary environments, and will hopefully illuminate modern biochemical processes while providing chemical insights into early metabolic events.

\section{ACKNOWLEDGMENTS}

Discussions with James B. Howard, Benedikt Schmid, Jessica Chiu, Pavel Strop, Oliver Einsle, Akif Tezcan, and Jonas Peters are greatly appreciated. Research in the author's laboratory was supported in part by U.S. Public Health Service grant GM45162.

\section{The Annual Review of Biochemistry is online at http://biochem.annualreviews.org}

\section{LITERATURE CITED}

1. Wächtershäuser G. 1992. Prog. Biophys. Mol. Biol. 58:85-201

2. Lippard SJ, Berg JM. 1994. Principles of Bioinorganic Chemistry. Mill Valley, CA: Univ. Sci. Books. 411 pp.

3. Holm RH, Solomon EI, eds. 1996. Chem. Rev. 96(7) 2237-3042

4. Messerschmidt A, Huber R, Poulos T, Wieghardt K, eds. 2001. Handbook of Metalloproteins. Chichester, UK: Wiley. $1472 \mathrm{pp}$.

5. Berg JM, Holm RH. 1982. In IronSulfur Proteins, ed. TG Spiro, pp. 1-66. New York: Wiley

6. Bertini I, Gray HB, Lippard SJ, Valentine SJ, eds. 1994. Bioinorganic Chemistry. Mill Valley, CA: Univ. Sci. Books. 592 pp.

7. Cowan JA. 1997. Inorganic Biochemistry: An Introduction. New York: WileyVCH. $440 \mathrm{pp}$.

8. Harding MM. 2001. Acta Crystallogr. D 57:401-11

9. Martinez SE, Huang D, Szczepaniak A, Cramer WA, Smith JL. 1994. Structure 2:95-105

10. Minor W, Steczko J, Bolin JT, Otwi- nowski Z, Axelrod B. 1993. Biochemistry 32:6320-23

11. Marcus RN, Sutin N. 1985. Biochim. Biophys. Acta 811:265-322

12. Gray HB, Winkler JR. 1996. Annu. Rev. Biochem. 65:537-61

13. Page CC, Moser CC, Chen XX, Dutton PL. 1999. Nature 402:47-52

14. Beinert H, Holm RH, Münck E. 1997. Science 277:653-59

15. Beinert H. 2000. J. Biol. Inorg. Chem. 5:2-15

16. Johnson MK. 1998. Curr. Opin. Chem. Biol. 2:173-81

17. Strop P, Takahara PM, Chiu H-J, Angove HC, Burgess BK, Rees DC. 2001. Biochemistry 40:651-56

18. Burgess BK, Lowe DJ. 1996. Chem. Rev. 96:2983-3011

19. Smith BE. 1999. Adv. Inorg. Chem. 47:159-218

20. Rees DC, Howard JB. 2000. Curr. Opin. Chem. Biol. 4:559-66

21. Schmid B, Chiu H-J, Ramakrishnan V, Howard JB, Rees DC. 2001. See Ref. 4, pp. 1025-36

22. Christiansen J, Dean DR, Seefeldt LC. 
2001. Annu. Rev. Plant Physiol. Plant Mol. Biol. 52:269-95

23. Navarro-Gonzalez R, McKay CP, Mvondo DN. 2001. Nature 412:61-64

24. Kasting JF, Siefert JL. 2001. Nature 412:26-27

25. Smil V. 2001. Enriching the Earth. Cambridge, MA: MIT Press

26. Hoehler TM, Bebout BM, Des Marais DJ. 2001. Nature 412:324-25

27. Jørgensen BB. 2001. Nature 412: 286-89

28. Bard AJ, Parsons R, Jordan J, eds. 1985. Standard Potentials in Aqueous Solution. New York: Marcel Dekker. 834 pp.

29. Thorneley RNF. 1992. Philos. Trans. $R$. Soc. London Ser. B 336:73-82

30. Howard JB, Rees DC. 1994. Annu. Rev. Biochem. 63:235-64

31. Seefeldt LC, Dean DR. 1997. Acc. Chem. Res. 30:260-66

32. Zimmermann R, Munck E, Brill WJ, Shah VK, Henzl MT, et al. 1978. Biochim. Biophys. Acta 537:185-207

33. Kim J, Rees DC. 1992. Science 257: 1677-82

34. Kim J, Rees DC. 1992. Nature 360: 553-60

35. Peters JW, Stowell MHB, Soltis SM, Finnegan MG, Johnson MK, Rees DC. 1997. Biochemistry 36:1181-87

36. Sørlie M, Christiansen J, Lemon BJ, Peters JW, Dean DR, Hales BJ. 2001. Biochemistry 40:1540-49

37. Bolin JT, Campobasso N, Muchmore SW, Morgan TV, Mortenson LE. 1993. See Ref. 128, pp. 186-95

38. Kim J, Woo D, Rees DC. 1993. Biochemistry 32:7104-15

39. Mayer SM, Lawson DM, Gormal CA, Roe SM, Smith BE. 1999. J. Mol. Biol. 292:871-91

40. Georgiadis MM, Komiya H, Chakrabarti P, Woo D, Kornuc JJ, Rees DC. 1992. Science 257:1653-59

41. Schlessman JL, Woo D, Joshua-Tor L,
Howard JB, Rees DC. 1998. J. Mol. Biol. 280:669-85

42. Jang SB, Seefeldt LC, Peters JW. 2000. Biochemistry 39:641-48

43. Jang SB, Seefeldt LC, Peters JW. 2000. Biochemistry 39:14745-52

44. Schindelin H, Kisker C, Schlessman JL, Howard JB, Rees DC. 1997. Nature 387:370-76

45. Chiu H-J, Peters JW, Lanzilotta WN, Ryle MJ, Seefeldt LC, et al. 2001. Biochemistry 40:641-50

46. Grossmann JG, Hasnain SS, Yousafzai FK, Smith BE, Eady RR. 1997. J. Mol. Biol. 266:642-48

47. Grossmann JG, Hasnain SS, Yousafzai FK, Smith BE, Eady RR, et al. 1999. Acta Crystallogr. D 55:727-28

48. Surerus KK, Hendrich MP, Christie PD, Rottgardt D, Orme-Johnson WH, Münck E. 1992. J. Am. Chem. Soc. 114:8579-90

49. Pierik J, Wassink H, Haaker H, Hagen R. 1993. Eur. J. Biochem. 212:51-61

50. Han JH, Beck K, Ockwig N, Coucouvanis D. 1999. J. Am. Chem. Soc. 121: 10448-49

51. McLean PA, Papaefthymiou V, OrmeJohnson WH, Münck E. 1987. J. Biol. Chem. 262:12900-3

52. Lee H-I, Hales BJ, Hoffman BM. 1997. J. Am. Chem. Soc. 119:11395-400

53. Yoo SJ, Angove HC, Papaefthymiou V, Burgess BK, Münck E. 2000. J. Am. Chem. Soc. 122:4926-36

54. Watt GD, Reddy KRN. 1994. J. Inorg. Biochem. 53:281-94

55. Angove HC, Yoo SJ, Münck E, Burgess BK. 1998. J. Biol. Chem. 273: 26330-37

56. Erickson JA, Nyborg AC, Johnson JL, Truscott SM, Gunn A, et al. 1999. Biochemistry 38:14279-85

57. Thorneley RNF, Lowe DJ. 1996. J. Biol. Inorg. Chem. 1:576-80

58. Dance I. 1996. J. Biol. Inorg. Chem. $1: 581-86$ 
59. Sellmann D, Sutter J. 1996. J. Biol. Inorg. Chem. 1:587-93

60. Coucouvanis D. 1996. J. Biol. Inorg. Chem. 1:594-600

61. Pickett CJ. 1996. J. Biol. Inorg. Chem. 1:601-6

62. Leigh GJ. 1995. Eur. J. Biochem. 229: 14-20

63. Leigh GJ. 1994. New J. Chem. 18: 157-61

64. Christie PD, Lee H-I, Cameron LM, Hales BJ, Orme-Johnson WH, Hoffman BM. 1996. J. Am. Chem. Soc. 118: 8707-9

65. Lee H-I, Cameron LM, Hales BJ, Hoffman BM. 1997. J. Am. Chem. Soc. 119:10121-26

66. George SJ, Ashby GA, Wharton CW, Thorneley RNF. 1997. J. Am. Chem. Soc. 119:6450-51

67. Thorneley RNF, Lowe DJ. 1985. In Molybdenum Enzymes, ed. TG Spiro, pp. 221-84. New York: Wiley

67a. Benton PMC, Mayer SM, Shao J, Hoffman BM, Dean DR, Seefeldt LC. 2001. Biochemistry 40:13816-25

68. Scott DJ, May HD, Newton WE, Brigle KE, Dean DR. 1990. Nature 343:188-90

69. Scott DJ, Dean DR, Newton WE. 1992. J. Biol. Chem. 267:20002-10

70. Newton WE, Dean DR. 1993. See Ref. 128, pp. 216-30

71. Kim C-H, Newton WE, Dean DR. 1995. Biochemistry 34:2798-808

72. Fisher K, Dilworth MJ, Kim C-H, Newton WE. 2000. Biochemistry 39:2970-79

73. Christiansen J, Cash VL, Seefeldt LC, Dean DR. 2000. J. Biol. Chem. 275: 11459-64

74. Weaver TM. 2000. Protein Sci. 9: 201-6

75. Popot J-L, Engelman DM. 2000. Аnnu. Rev. Biochem. 69:881-922

76. Adams MWW, Mortenson LE, Chen JS. 1981. Biochim. Biophys. Acta 594: 105-76

77. Adams MWW. 1990. Biochim. Biophys. Acta 1020:115-45
78. Albracht SPJ. 1994. Biochim. Biophys. Acta 1188:167-204

79. Stiefel EI, Graham NG. 1994. See Ref. 6, pp. 365-453

80. Adams MWW, Stiefel EI. 2000. Curr. Opin. Chem. Biol. 4:214-20

81. Nicolet Y, Lemon BJ, FontecillaCamps JC, Peters JW. 2000. Trends Biochem. Sci. 25:138-43

81a. Vignais PM, Billoud B, Meyer J. 2001. FEMS Microbiol. Rev. 25:455-501

82. Peters JW. 1999. Curr. Opin. Struct. Biol. 9:670-76

83. Lemon BJ, Peters JW. 2001. See Ref. 4, pp. 738-51

84. Peters JW, Lanzilotta WN, Lemon BJ, Seefeldt LC. 1998. Science 282: 1853-58

85. Nicolet Y, Piras C, Legrand P, Hatchikian CE, Fontecilla-Camps JC. 1999. Struct. Fold. Des. 7:13-23

86. van der Spek T, Arendsen AF, Happe RP, Yun S, Bagley KA, et al. 1996. Eur. J. Biochem. 237:629-34

87. Nicolet $Y$, de Lacey AL, Vernède X, Fernandez VM, Hatchikian EC, Fontecilla-Camps JC. 2001. J. Am. Chem. Soc. 123:1596-601

88. Fan H-J, Hall MB. 2001. J. Am. Chem. Soc. 123:3828-29

89. Lemon BJ, Peters JW. 1999. Biochemistry 38:12969-73

90. Bennett B, Lemon BJ, Peters JW. 2000. Biochemistry 39:7455-60

91. Cao ZX, Hall MB. 2001. J. Am. Chem. Soc. 123:3734-42

92. Volbeda A, Charon M-H, Piras C, Hatchikian EC, Frey M, FontecillaCamps JC. 1995. Nature 373:580-87

93. Frey M, Fontecilla-Camps JC, Volbeda A. 2001. See Ref. 4, pp. 880-96

94. Volbeda A, Garcin E, Piras C, de Lacey AL, Fernandez VM, et al. 1996. J. Am. Chem. Soc. 118:12989-96

95. Pierik AJ, Roseboom W, Happe RP, Bagley KA, Albracht SPJ. 1999. J. Biol. Chem. 274:3331-37

96. Garcin E, Vernède X, Hatchikian EC, 
Volbeda A, Frey M, Fontecilla-Camps JC. 1999. Structure 7:557-66

97. Dobbek H, Gremer L, Meyer O, Huber R. 1999. Proc. Natl. Acad. Sci. USA 96:8884-89

98. Meyer O, Gremer L, Ferner R, Ferner M, Dobbek H, et al. 2000. Biol. Chem. 381:865-76

99. Ferry JG. 1995. Annu. Rev. Microbiol. 49:305-33

100. Ragsdale SW, Kumar M. 1996. Chem. Rev. 96:2515-39

101. Ermler U, Grabarse W, Shima S, Goubeaud M, Thauer RK. 1998. Curr. Opin. Struct. Biol. 8:749-58

102. Dobbek H, Svetlitchnyi V, Gremer L, Huber R, Meyer O. 2001. Science 293: 1281-85

103. Drennan CL, Heo J, Sintchak MD, Schreiter E, Ludden PW. 2001. Proc. Natl. Acad. Sci. USA 98:11973-78

104. Volbeda A, Fontecilla-Camps JC, Frey M. 1996. Curr. Opin. Struct. Biol. 6:804-12

105. Dobbek H, Gremer L, Meyer O, Huber R. 2001. See Ref. 4, pp. 1136-47

106. Arendsen AF, Lindley PF. 1999. Adv. Inorg. Chem. 47:219-49

107. Arendsen AF, Hadden J, Card G, McAlpine AS, Bailey S, et al. 1998. J. Biol. Inorg. Chem. 3:81-95

108. Cooper SJ, Garner CD, Hagen WR, Lindley PF, Bailey S. 2000. Biochemistry 39:15044-54

109. Berks BC, Ferguson SJ, Moir JWB, Richardson DJ. 1995. Biochim. Biophys. Acta 12232

110. Zumft WG. 1997. Microbiol. Mol. Biol. Rev. 61:533-616

111. Richardson DJ, Watmough NJ. 1999. Curr. Opin. Chem. Biol. 3:207-19

112. Rosenzweig AC. 2001. Nat. Struct. Biol. 7:169-71

113. Brown K, Tegoni M, Prudêncio M, Pereira AS, Besson S, et al. 2000. Nat. Struct. Biol. 7:191-95
114. Brown K, Djinovic-Carugo K, Haltia T, Cabrito I, Saraste M, et al. 2000. J. Biol. Chem. 275:41133-36

115. Rasmussen T, Berks BC, SandersLoehr J, Dooley DM, Zumft WG, Thomson AJ. 2000. Biochemistry 39:12753-56

116. Westcott BL, Gruhn NE, Enemark JH. 1998. J. Am. Chem. Soc. 120:3382-86

117. Hille B, Schwarz W. 1978. J. Gen. Physiol. 72:409-42

118. Heckmann K. 1972. In Biomembranes, ed. F Kreuzer, JFG Slegers, pp. 127-53. New York: Plenum

119. Chen KS, Hirst J, Camba R, Bonagura CA, Stout CD, et al. 2000. Nature 405: 814-17

120. Murzin AG, Brenner SE, Hubbard T, Chothia C. 1995. J. Mol. Biol. 247: 536-40

121. Zouni A, Witt H-T, Kern J, Fromme P, Krauß N, et al. 2001. Nature 409: 739-43

121a. Carrell TG, Tyryshkin AM, Dismukes GC. 2002. J. Biol. Inorg. Chem. 7:2-22

122. Nguyen H-HT, Nakagawa KH, Hedman B, Elliott SJ, Lidstrom ME, et al. 1996. J. Am. Chem. Soc. 118:12766-76

123. Shah VK, Allen JR, Spangler NJ, Ludden PW. 1994. J. Biol. Chem. 269: 1154-58

124. Sussman JL, Lin DW, Jiang JS, Manning NO, Prilusky J, et al. 1998. Acta Crystallogr. D 54:1078-84

125. Berman HM, Westbrook J, Feng Z, Gilliland G, Bhat TN, et al. 2000. Nucleic Acids Res. 28:235-42

126. Kraulis PJ. 1991. J. Appl. Crystallogr. 24:946-50

127. Kabsch W, Sander C. 1983. Biopolymers 22:2577-637

128. Stiefel EI, Coucouvanis D, Newton WE, eds. 1993. Molybdenum Enzymes, Cofactors and Model Systems. ACS Symp. Ser. 535. Washington, DC: Am. Chem. Soc. 


\section{CONTENTS}

FrontISPIECE-Norman Davidson xii

My Career in Molecular Biology, Norman Davidson xiii

FrontisPIECE-Thressa Campbell Stadtman xxvi

Discoveries of Vitamin $B_{12}$ And Selenium Enzymes, Thressa Campbell Stadtman

Error-Prone Repair DNA Polymerases in Prokaryotes and EUKARYOTES, Myron F. Goodman 17

Long-Distance Electron Transfer Through DNA, Bernd Giese 51

The Bacterial RecA Protein and the Recombinational DNA Repair of Stalled Replication Forks, Shelley L. Lusetti and Michael M. Cox 71

V(D)J Recombination: RAG Proteins, Repair Factors, AND Regulation, Martin Gellert

EukARYotic DNA Polymerases, Ulrich Hübscher, Giovanni Maga, and Silvio Spadari

Eukaryotic Ribonuclease P: A Plurality of Ribonucleoprotein EnZymes, Shaohua Xiao, Felicia Scott, Carol A. Fierke, and David R. Engelke

Active Site Tightness and Substrate Fit in DNA Replication, Eric T. Kool

Great Metalloclusters in Enzymology, Douglas C. Rees

ATP-Dependent Nucleosome Remodeling, Peter B. Becker and Wolfram Hörz

Biological Roles of Proteases in Parasitic ProtozoA, Michael Klemba and Daniel E. Goldberg

Metabolism and the Control of Circadian Rhythms, Jared Rutter, Martin Reick, and Steven L. McKnight

DNA Replication in Eukaryotic Cells, Stephen P. Bell and Anindya Dutta

The La Protein, Sandra L. Wolin and Tommy Cedervall

Lipoprotein ReCEPTORS IN THE NeRvous System, Joachim Herz and Hans H. Bock 
Order Out of Chaos: Assembly of Ligand Binding Sites in Heparan Sulfate, Jeffrey D. Esko and Scott B. Selleck

Neuronal $\mathrm{CA}^{2+} /$ Calmodulin-Dependent Protein Kinase II: The Role of Structure and Autoregulation in Cellular Function, Andy Hudmon and Howard Schulman

Biochemistry of NA,K-ATPAse, Jack H. Kaplan

Mammalian ABC Transporters in Health and Disease, $P$. Borst and R. Oude Elferink

Homogeneous Glycopeptides and GLyCOPROTEINS FOR BiologicAL Investigation, Michael J. Grogan, Matthew R. Pratt, Lisa A. Marcaurelle, and Carolyn R. Bertozzi

LiPOPOLYSACCHARIDE ENDOTOXINS, Christian R. H. Raetz and Chris Whitfield

Formation of Unusual Sugars: Mechanistic Studies and Biosynthetic Applications, Xuemei M. He and Hung-wen Liu

Nuclear Actin and Actin-Related Proteins in Chromatin Remodeling, Ivan A. Olave, Samara L. Reck-Peterson, and Gerald R. Crabtree

Mechanisms of Fast Protein Folding, Jeffrey K. Myers and Terrence G. Oas

RNA Editing by Adenosine Deaminases That Act on RNA, Brenda L. Bass

Catalytic Proficiency: The Unusual Case of OMP Decarboxylase, Brian G. Miller and Richard Wolfenden

Catalytic Strategies of the Hepatitis Delta Virus Ribozymes, I-hung Shih and Michael D. Been

INDEXES

$\begin{array}{ll}\text { Author Index } & 919\end{array}$

Subject Index $\quad 995$

Cumulative Index of Contributing Authors, Volumes 67-71 1035

Cumulative Index of Chapter Titles, Volumes 67-71

\section{ERRATA}

An online log of corrections to Annual Review of Biochemistry chapters may be found at http://biochem.annualreviews.org/errata.shtml 